\title{
El uso obligatorio de la escritura notarial en las transacciones comerciales en Barranquilla, 1849-1898*
}

Tomás Caballero Truyol

\begin{abstract}
Profesor de la Universidad del Atlántico (Colombia). Correo electrónico: tomascabatru@hotmail.com. El autor es doctor en Historia de América Latina, Mundos Indígenas de la Universidad Pablo de Olavide (España). Integrante del Grupo de Investigaciones Históricas en Educación e Identidad Nacional (Categoría A, Colciencias), grupo interinstitucional de la Universidad del Atlántico (Colombia), Universidad de Caldas (Colombia) y Universidad de Tolima (Colombia). Entre sus publicaciones recientes tenemos: "Entre los negocios y la familia: Mujer, crédito y sociedad en Barranquilla (Colombia), 1849-1900”" en Historelo Vol. 9 No. 17 (2017) y "Comerciantes y casas comerciales relacionados con las actividades financieras en una ciudad caribeña de Colombia durante la segunda mitad del siglo XIX" en Anuario de Historia Regional y de las Fronteras Vol. 20 (2015).
\end{abstract}

\footnotetext{
Recibido: 18 de julio de 2016

Aprobado: 21 de septiembre de 2016

Modificado: 22 de diciembre de 2016

Artículo de investigación científica
}

DOI: http://dx.doi.org/10.15648/hc.32.2018.5

Este artículo forma parte del proyecto de la tesis doctoral titulada: "Formación del mercado financiero en la ciudad de Barranquilla (Colombia) durante la segunda mitad del siglo XIX" financiación propia.

Esta publicación está bajo una licencia Creative Commons Reconocimiento-NoComercial 4.0 
E1 uso obligatorio de la escritura notarial en las transacciones comerciales en Barranquilla, 1849-1898

\title{
Resumen
}

Este trabajo analiza el uso de la escritura de obligación como el principal mecanismo financiero para transmitir capitales en diferentes sectores de la economía barranquillera en la segunda mitad del siglo XIX. También examina el comportamiento y las fluctuaciones del mercado crediticio mediante variables sociales, políticas y económicas que alteraron su ritmo, causando auge, estancamiento y crisis en diferentes períodos.

Palabras clave: obligación, crédito, mercado, economía y crisis.

The mandatory use of notarial deeds in the business transactions in Barranquilla, 1849-1898

\begin{abstract}
This article analyses the use of public deeds as the main financial mechanism in order to transmit capitals (monetary) to different sectors of Barranquilla economics in the second half of the nineteenth century. It also examines the behavior and fluctuations of the credit market through social, political and economic variables, which altered its pace, causing rising, stagnation and crisis in different periods.
\end{abstract}

Key words: mandatory, credit, market, economics, crisis.

O uso obrigatório da escritura notarial nas transacções comerciais na cidade de Barranquilla, 1849-1898

\section{Resumo}

Este trabalho analisa o uso da escritura de obrigação como o principal mecanismo financeiro para transmitir capitais em diferentes sectores da economia barranquillera na segunda metade do século XIX. Também examina o comportamento e as flutuações do mercado crediticio mediantes variáveis sociais, políticas e económicas que alteraram seu ritmo, causando auge, estancamento e crise em diferentes períodos.

Palavras-chave: obrigação, crédito, mercado, economia e crise. 
L'usage obligatoire de l'acte notarié au cours des transactions commerciales dans la ville de Barranquilla, 1849-1898

\section{Résumé}

Cette étude fait l'analyse de l'usage de l'acte notarié d'obligation comme le principal mécanisme financier pour transférer des capitaux dans différents secteurs de l'économie de Barranquilla pendant la moitié du XIXème siècle. En plus, le texte examine le comportement et les variations du marché de crédit à travers les variables sociales, politiques et économiques qui ont modifié son rythme entrainant essor, stagnation et crise dans des périodes différentes.

Mots clés: obligation, crédit, marché, économie, crise.

\section{INTRODUCCIÓN}

En los últimos años los estudios sobre la historia financiera han crecido significativamente en América Latina, por ejemplo, México es uno de los países de la región con una rica historiografía sobre el crédito, la banca y la moneda ${ }^{1}$. Los economistas, sociólogos, historiadores y otros científicos sociales se han interesado en estos temas por diversos motivos. Uno de ellos ha sido la necesidad de comprender las dinámicas del sistema monetario en relación a la creación de los primeros bancos comerciales y centrales de la región y su impacto económico en la sociedad. Igualmente, se han preocupado por la evolución del sistema financiero y el crédito desde la era republicana hasta la actualidad ${ }^{2}$.

1 Gustavo A. Del Ángel y Carlos Marichal, "Poder y crisis: historiografía reciente del crédito y la banca en México, siglos XIX y XX”, Historia mexicana, Vol. 52, No. 3 (2012), 677-724; Gisela Von Wobeser, Mecanismos crediticios en la Nueva España el uso del censo consignativo, Mexican studies/ Estudios mexicanos, Vol. 5, No. 1 (1989): 1-23; Ricardo Solís, "La crisis gemela (los problemas de la balanza de pagos y bancaria) de 1913 y sus efectos en la moneda y los bancos", América Latina en la historia económica Vol. 23, No. 3 (2016), 115-146.

2 Marcelo Rougier (compilador), La banca de desarrollo en América Latina. Luces y sombras en la industrialización en la región (Buenos Aires: Fondo de Cultura Económica, 2011); Marcia Luz Solórzano, "Banca extranjera en América Latina (1830-1910) una alternativa de transformación de las relaciones deuda-crédito", Revista Nicolaita de Estudios Económicos, Vol. 2, No. 2 (2013), 77-95; Alfonso Quiroz, "Grupos económicos y decisiones financieras en el Perú, 1884-1930", Apuntes: Revista de Ciencias Sociales, No. 19 (2015): 73-108; Alfonso Quiroz, Banqueros en conflicto: estructura 
En Colombia los estudios de historia económica también se incrementaron en las últimas décadas y se centraron en analizar el comportamiento de la banca, las finanzas, las empresas y el sistema monetario. Igualmente, como en el caso mexicano se han enfocado por entender y explicar la relación entre las esferas de poder político y el desarrollo económico experimentado en el país en más de 200 años de independencia. Sin lugar a dudas, muchos de estos trabajos apoyados en métodos cuantitativos demuestran que la historia económica y financiera del país es dinámica y compleja ${ }^{3}$.

En este sentido, el presente trabajo se enmarca en los estudios de historia económica que analizan las dinámicas monetarias y financieras de una sociedad pretérita. En nuestro caso, estudiamos las transacciones crediticias que se realizaron en Barranquilla durante la segunda mitad del siglo XIX mediante documentos registrados en escrituras notariales con el propósito de analizar el comportamiento del sistema financiero en diferentes coyunturas económicas que se presentaron a lo largo de 50 años, causando auge, crisis y estancamiento en la economía local.

Para observar el comportamiento del crédito y su impacto en la economía se revisaron principalmente las escrituras de obligaciones y las cancelaciones registradas en el Archivo de la Notaría Primera de Barranquilla (ANPB),

financiera y economía peruana, 1884-1930 (Lima: Centro de Investigación/Universidad del Pacífico, 1989); Luis Felipe Zegarra, "Women and credit in Peru during the guano era. Was there gender discrimination in the mortgage credit market of Peru?, Historia Económica, No. 32 (2014),151-185; y Heras Raúl García, "Deuda externa, banca internacional y política económica: los comienzos de una relación perdurable en la Argentina 1955-1973”, Revista de la historia de la economía y de la empresa, No. 8 (2014), 345-377.

3 Richard Preston, "El crédito y la economía", en Sociedad y economía en el Valle del Cauca, Tomo IV (Bogotá: Biblioteca Banco Popular, 1983); Mauricio Avella, Pensamiento y política monetaria en Colombia, 1886-1945 (Bogotá: Contraloría General de la República, 1987); Adolfo Meisel, El Banco de la República: antecedentes, evolución y estructura (Bogotá: Editorial Banco de la República, 1990); Carlos Caballero y Miguel Urrutia, Historia del sector financiero colombiano en el siglo XX (Bogotá: Editorial Norma, 2006); Miguel Urrutia y Olga Marcela Namen León, Historia del crédito hipotecario en Colombia (Bogotá: Universidad de los Andes, 2011); James Moreno Torres, "Precios, oferta monetaria y crecimiento económico en la Nueva Granada de la segunda mitad del siglo XVIII", Revista de Economía Institucional, Vol. 15, No. 29 (2013), 195-225; Kelly Acuña Mantilla y Andrés Álvarez, "De la moneda metálica al billete de banco en Medellín y Bogotá (1871-1885): Complementariedad y sustitución de medios de pago en un Régimen de banca libre", Revista Tiempo \& Economía, No. 1, (2014). 
ya que estos documentos detallan el valor de los préstamos, los réditos, los plazos, las prórrogas, los bienes gravados y los nombres de los prestamistas y los prestatarios. La información obtenida permitió construir series estadísticas que mediante un análisis cuantitativo reflejaron parcialmente el ritmo del crédito en la ciudad de Barranquilla, pues la falta de acceso a otros documentos como los bancarios y los libros de cuentas de los comerciantes y prestamistas dificultaron tener una visión más compleja sobre el sistema crediticio.

Sin embargo, las fuentes consultadas permitieron identificar los principales instrumentos financieros usados en las transacciones comerciales y determinar que la escritura de obligación fue el título que más aceptación tuvo en el mercado local durante 1849 y 1898. El gran número de operaciones económicas realizadas con este documento fue el producto de las imposiciones realizadas por los comerciantes y prestamistas para garantizar el retorno de sus dineros dados a préstamos en un mercado que era volátil y riesgoso por causas de factores sociales, políticos y económicos que alteraron su dinámica en diferentes momentos. En este sentido, el uso de este instrumento y de otros simularon la circulación de capitales en el papel porque generalmente las transacciones como las compraventas se efectuaban en la notaría donde se emulaba el pago en dinero en efectivo mediante un documento escriturado que se transformaba en un préstamo al diferir el pago de la operación en plazos.

El artículo está estructurado en tres partes: la primera, aborda la definición de la obligación y su implementación en el comercio local en relación a otros documentos financieros. La segunda, identifica y explica los ciclos del crédito durante los años de 1849 y 1898. Y la última, se enfoca en analizar el auge y la decadencia del crédito en las dos últimas décadas del siglo XIX.

\section{Definición, uso y Características de la obligación}

Según el Código Civil de $1873^{4}$, la obligación era un contrato civil entre

4 Código Civil Nacional (Bogotá: Imprenta de Gaitán, 1873), 183. 
dos o más personas llamadas acreedor y deudor respectivamente. El primero prestaba cierta cantidad de dinero o su equivalente al segundo para que lo devolviera en un tiempo determinado, más los premios o intereses generados. De este modo, prestamista y prestatario se obligaban a cumplir los términos pactados en el contrato registrados en una escritura pública. Este documento no podía modificarse, ni destruirse, a menos que ambas partes lo acordaran previamente o se cancelara el valor total de la obligación. En otros términos, el acreedor se obligaba a prestar el dinero en efectivo o su equivalente en una fecha estipulada, y el prestatario a pagar la misma suma y los intereses en un plazo prorrogable o improrrogable.

En este sentido, la obligación se constituía en un título financiero para reconocer o conceder un crédito a corto o a mediano plazo, ya que creaba un vínculo jurídico entre el acreedor y el deudor. Era prorrogable cuando el plazo para cancelarlo se podía ampliar. Generalmente ocurría cuando el deudor no pagaba la acreencia en la fecha acordada, fijándose una nueva bajo los mismos términos. Era improrrogable cuando el plazo era inmodificable y debía pagarse antes o el mismo día de su vencimiento. Un alto porcentaje de las fuentes consultadas no señalan si eran o no prorrogables; solo detallan el valor de las transacciones, los intereses y los bienes gravados a favor de los prestamistas. Sin embargo, podemos afirmar que los plazos para cancelar los créditos se ampliaban automáticamente hasta su cancelación definitiva. Esto se puede evidenciar, ya que el $70 \%$ de las 736 obligaciones registradas fueron pagadas en fechas posteriores a las pactadas, sin ningún tipo de avisos o anotaciones notariales.

Un ejemplo fue la transacción realizada el 11 de mayo de 1859, en la cual don Esteban Márquez ${ }^{5}$ otorgó un préstamo por la suma de $\$ 300$ pesos de ocho décimos al señor Francisco Páez con el gravamen de dos casas en la calle de San Juan. El plazo para su cancelación fue 4 meses prefijos improrrogables con un interés del $3 \%$ mensual $^{6}$. Pero, el crédito no se pagó en

$5 \quad$ Fue uno los hombres más pudientes e influyentes de la sociedad barranquillera en el siglo XIX con inversiones en diversos sectores de la economía local y regional, principalmente en el comercio y el sector financiero. Véase: Sergio Solano y Jorge Conde, élite empresarial y desarrollo industrial en Barranquilla 1875-1930 (Barranquilla: Universidad del Atlántico, 1993), 16.

6 Escritura de obligación (1859), ANPB, t. único, e. 47. 
la fecha pactada, sino el 24 de enero de 1862, sin ningún tipo de prórroga o acuerdo notarial ${ }^{7}$. Para el señor Márquez era algo común este tipo de práctica, ya que generalmente concedía nuevos plazos de manera informal a los clientes que puntualmente pagan sus réditos.

Otro caso fue el crédito otorgado el 30 de enero de 1868 por Rundencido Cantillo a favor de la señora Mercedes Felipe por $\$ 300$ pesos, el cual no generaba intereses si pagaba en un solo plazo y se cobraría una tasa usurera del $2 \%$ mensual si era cancelado después de un mes. La fecha de pago fue fijada en nueve meses prefijos y nueve más si no era cancelado en el tiempo estipulado ${ }^{8}$. La deudora no pagó la obligación en el plazo convenido por falta de solvencia económica y prolongó su cancelación hasta 1875, es decir, 7 años después de lo acordado legalmente?

Los ejemplos señalados demuestran que las prórrogas eran muy comunes durante los préstamos registrados en las escrituras públicas, siempre y cuando los prestatarios cancelaran puntualmente los intereses o concedieran nuevas garantías de pagos. Asimismo, el documento de obligación era útil en el comercio porque minimizaba los riesgos financieros por tener dos propósitos: primero, determinaba el valor de la transacción acordada entre prestamista y prestatario; y segundo, garantizaba el pago del préstamo mediante el gravamen de un bien raíz o mueble. Estas dos condiciones fueron determinantes para que los comerciantes-prestamistas de la época como Esteban Márquez implementaran su uso al momento de conceder un crédito, pues era una garantía real de pago que aseguraba a los acreedores el retorno de los capitales prestados.

Por eso se puede observar en la Tabla 1 que fue el instrumento financiero más aceptado en el mercado en comparación a otros como la letra de cambio, la hipoteca, la retroventa y el censo, por la flexibilidad y confianza que brindaba a los prestamistas y prestatarios cuando negociaban un crédito. Mientras que los otros títulos eran regidos en el sentido que solo podían

7 Escritura de cancelación (1862), ANPB, t. 1, e. 14.

8 Escritura de obligación (1868), ANPB, t. único, e. 25.

$9 \quad$ Escritura de cancelación (1875), ANPB, t. único, e. 91. 
utilizarse en negocios específicos como por ejemplo para comprar viviendas o trasferir dineros entre diferentes plazas.

En el caso de la hipoteca, es un documento que ha sido históricamente usado en el comercio para financiar la compra de viviendas y bienes inmuebles a largo plazo. Este instrumento era poco empleado en el comercio local porque los prestamistas no estaban dispuestos a arriesgar sus capitales por mucho tiempo, sobre todo en una economía volátil como la de Barranquilla en el siglo XIX, donde un alto porcentaje de la población vivía con bajos ingresos provenientes principalmente de labores agrícolas y pancoger, es decir, de una economía de subsistencia que según los relatos de Élisée Reclus $^{10}$, solo permitía adquirir unos pocos bienes materiales. En consecuencia, los comerciantes-prestamistas desestimularon su uso y prefirieron la escritura de obligación (ver Tabla 1) porque cumplía con la misma finalidad de una hipoteca, pero con plazos más cortos para cancelar un crédito, reduciendo de esta manera los riesgos financieros que podían generar los préstamos por tiempos muy prolongados y costosos para las familias que destinaban la mayor parte de sus salarios para los gastos de alimentos y el restante para subsanar otros compromisos socioeconómicos.

Tabla 1. Número y valor de transacciones financieras por tipos de documentos notariales, 1849-1898 ${ }^{11}$

\begin{tabular}{|l|c|c|c|}
\hline \multirow{2}{*}{ Tipo de Documento } & No. & \multirow{2}{*}{$*$} & Valor * \\
\cline { 2 - 3 } & Transacciones & & \\
\hline Obligación & 728 & 94,178 & 907286.63 \\
\hline Retroventa & 28 & 3,622 & 37908.3 \\
\hline Hipoteca & 8 & 1,034 & 78.913 \\
\hline Endoso & 7 & 0,904 & 6028.75 \\
\hline Censo & 2 & 0,25 & 2.010 \\
\hline Total & 773 & 99,98 & $1.032 .146,68$ \\
\hline
\end{tabular}

Fuente: ANPB, 1849-1889

*Valor en pesos de ocho décimos

En el caso de la retroventa, por ejemplo, solo se realizaron 28 operaciones

10 Élisée Reclus, Viaje a la Sierra Nevada de Santa Marta (Bogotá: Colcultura, 1992), 73-75

11 Cuadro elaborado por el autor a partir de fuentes notariales. 
bajo esa figura crediticia con la cual se transfirieron $\$ 37.908$ pesos de ocho décimos a la economía (ver Tabla 1). Su poca aceptación se debe a que era un contrato jurídico que simulaba la compra y venta de una propiedad en la cual el vendedor se reservaba el derecho de comprarla nuevamente en un plazo estipulado a so pena de perderla. Estas características la convirtieron en un instrumento poco atractivo para realizar un negocio, ya que la mayoría de la población no contaba con una propiedad, requisito indispensable para acceder a un crédito por esta vía.

Además, los plazos fijados para sus pagos eran demasiado cortos e improrrogables. En este sentido, la obligación era más laxa para los intereses personales de los prestatarios porque les permitía obtener préstamos bajo las mismas condiciones que los registrados en una retroventa con o sin el gravamen de un bien inmueble; también se podía respaldar con otros patrimonios. Incluso, para los deudores no era tan agobiante el pago de una obligación registrada en una escritura notarial cuando se vencían los términos para cancelarla, el buen comportamiento en los pagos de los réditos pactados con los acreedores les aseguraba prácticamente tener nuevas prórrogas sin ver amenazadas sus propiedades. De hecho, durante el período estudiado fueron pocos los prestamistas que recurrieron a los estrados judiciales para iniciar procesos de remates sobre las propiedades que estaban gravadas con créditos vencidos como se observa en la Tabla. 2. Inferimos que el bajo número de remates que hubo en el mercado se debió al buen comportamiento en los pagos de las deudas por parte de los prestatarios y a los nuevos acuerdos que llegaban de manera informal con sus acreedores.

Tabla 2. Número de remates entre 1849 y 1886

\begin{tabular}{|c|c|c|}
\hline Año & No. Remates & Valor en pesos de ocho decimos \\
\hline 1862 & 1 & 400 \\
\hline 1875 & 1 & 4800 \\
\hline 1881 & 2 & 400 \\
\hline 1882 & 5 & 370 \\
\hline 1883 & 3 & 5785 \\
\hline 1884 & 2 & 440 \\
\hline 1886 & 1 & 267 \\
\hline Total & 15 & $\$ 12.462$ \\
\hline
\end{tabular}

Fuente: ANPB, 1849-1900 
En resumen, la obligación fue el título financiero con mayor aceptación en el comercio local porque se adaptó rápidamente a las dinámicas económicas de la ciudad y las de sus habitantes, acostumbrados a vivir con pocos ingresos provenientes generalmente de labores agrícolas. De esta manera, permitió transferir pequeñas y grandes sumas de capitales en forma de créditos hacia distintos renglones de la economía de forma rápida y confiable para financiar cualquier tipo de negocio o solucionar un problema de orden socioeconómico.

\section{LOS CICLOS DEL CRÉDITO}

Las obligaciones crediticias y las cancelaciones recolectadas en la documentación notarial referente a la ciudad de Barranquilla entre 1849 y 1898 arrojan una serie muy fluctuante, como se observa en el Gráfico 1, marcada por 9 ciclos donde hubo crecimientos, contracciones y recuperaciones que alteraron las dinámicas de las actividades financieras desarrolladas en el comercio local.

\section{Gráfico 1}

El ritmo del crédito entre 1849 y $1898^{12}$

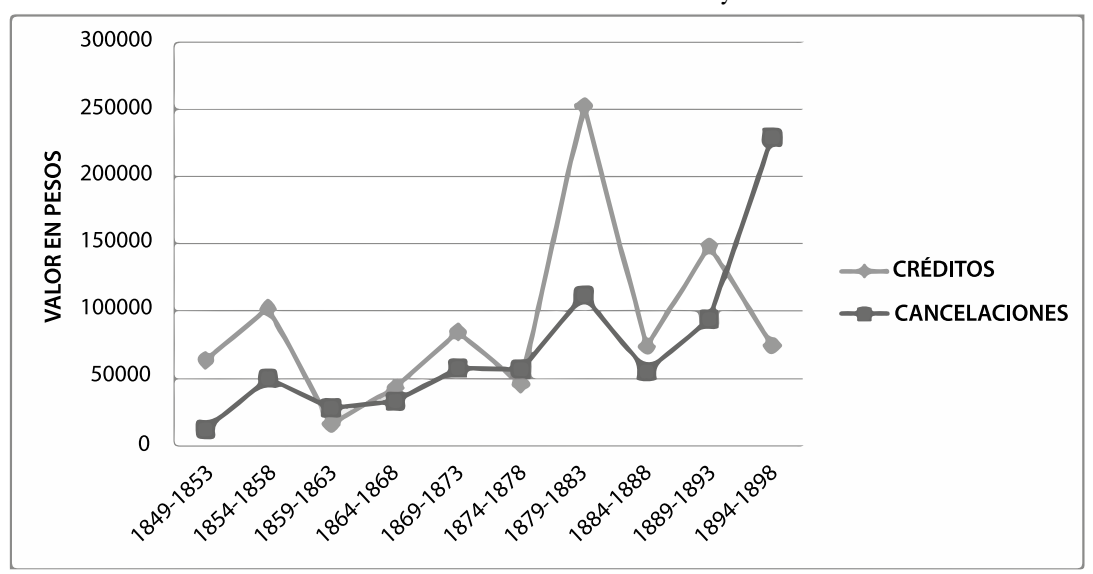

Fuente: ANPB, 1849-1898

El primero de ellos comprendido entre 1849 y 1853, fue un período de rápido crecimiento; se realizaron un total de 102 obligaciones por valor de \$63.788,9 pesos de ocho décimos. Las cifras obtenidas permiten señalarlo

12 Gráfico elaborado por el autor mediante escrituras de obligaciones y cancelaciones. 
como uno de los períodos con mayor número de transacciones (ver Tabla 3). Lo anterior se puede explicar por factores de orden socioeconómico. Uno de ellos fue la epidemia de cólera que diezmó una parte de los habitantes del Caribe colombiano durante los años de 1850. En el caso de Barranquilla, la epidemia aumentó el fervor religioso hacia San Roque, pero también actuó como una especie de catalizador en el mercado financiero que creció de forma vertiginosa porque muchas personas afectadas por la enfermedad recurrieron al crédito para satisfacer sus necesidades económicas. Un ejemplo fue el préstamo que obtuvieron en noviembre de 1856 las señoras Bernarda Hernández y Mercedes Camacho por parte del comerciante Nicolás Salcedo por la suma de $\$ 250$ pesos para el pago de los gastos causados por la enfermedad, muerte y entierro de su abuela ${ }^{13}$.

Tabla 3. Números, porcentajes y valores de créditos por períodos ${ }^{14}$

\begin{tabular}{|c|r|r|r|r|}
\hline Años & No. Créditos & $\%$ & \multicolumn{1}{|c|}{ Valor* } & $\%$ \\
\hline $1849-1853$ & 102 & 14 & $63.788,9$ & 7 \\
\hline $1854-1858$ & 110 & 15 & $102.564,41$ & 11 \\
\hline $1859-1863$ & 40 & 5 & 16.533 & 2 \\
\hline $1864-1868$ & 57 & 8 & $43.345,9$ & 5 \\
\hline $1869-1873$ & 56 & 8 & $85.014,12$ & 9 \\
\hline $1874-1878$ & 45 & 6 & 46.038 & 5 \\
\hline $1879-1883$ & 104 & 14 & $252.562,2$ & 28 \\
\hline $1884-1888$ & 64 & 9 & $74.018,97$ & 8 \\
\hline $1889-1893$ & 92 & 13 & $149.192,13$ & 17 \\
\hline $1894-1898$ & 58 & 8 & 74.230 & 8 \\
\hline TOTAL & 728 & 100 & $907.287,63$ & 100 \\
\hline
\end{tabular}

Fuente: ANPB, 1849-1898

*Valores en pesos de ocho décimos

Quizás fueron varias las familias que siguieron el ejemplo anterior, es decir, se endeudaron para pagar los gastos originados por la enfermedad de un pariente cercano, ya que los ingresos obtenidos por sus empleos eran bajos y eventuales, generalmente dependían de los ciclos agrarios y ganaderos $^{15}$. Hechos que dispararon el número de préstamos y estancaron el

13 "Escritura de obligación” (1856), ANPB, t. único, e. 200.

14 Gráfico elaborado por el autor mediante escrituras de obligaciones y cancelaciones.

15 Sergio Paolo Solano, "Formas salariales y salario justo en el Caribe colombiano, 1850-1930", Revista Amauta, No. 15 (2010), 159-181. 
pago de las deudas (ver Tabla 4, Gráfico 1). La alta morosidad reflejada en el bajo número de las cancelaciones también se puede explicar como una consecuencia socioeconómica producto del cólera que fue contraído por muchos deudores que dejaron de trabajar para poder recuperar su salud. La interrupción en los pagos afectó económicamente a los agiotistas que tuvieron que esperar meses y años para recuperar los capitales invertidos. Pero los créditos desembolsados en su mayoría estaban respaldados con propiedades raíces que redujeron la selección adversa del mercado, convirtiéndolos en elementos lucrativos por las altas utilidades que generaban los intereses con los cuales estaban gravados.

Tabla 4. Números, porcentajes y valores de las cancelaciones por cuatrienios ${ }^{16}$

\begin{tabular}{|c|c|r|c|c|}
\hline Años & No. Cancelaciones & $\%$ & Valor en pesos de ocho décimos & $\%$ \\
\hline $1849-1853$ & 20 & 4 & $12.380,86$ & 2 \\
\hline $1854-1858$ & 67 & 12 & $49.709,55$ & 7 \\
\hline $1859-1863$ & 40 & 7 & 27.817 & 4 \\
\hline $1864-1868$ & 39 & 7 & $33.061,7$ & 4 \\
\hline $1869-1873$ & 36 & 7 & $57.643,66$ & 8 \\
\hline $1874-1878$ & 41 & 8 & 56.744 & 8 \\
\hline $1879-1883$ & 76 & 14 & 111.495 & 15 \\
\hline $1884-1888$ & 52 & 10 & $55.416,95$ & 8 \\
\hline $1889-1893$ & 93 & 17 & $93.961,5$ & 13 \\
\hline $1894-1898$ & 76 & 14 & $229.011,96$ & 31 \\
\hline TOTAL & 540 & 100 & $727.242,18$ & 100 \\
\hline
\end{tabular}

Fuente: ANPB, 1849-1898

De esta forma, cuando en 1853 se reiniciaron los pagos de las cancelaciones crediticias (ver Tabla 5), los plazos de algunas acreencias adquiridas en meses y años anteriores estaban vencidos. Ello infló sus valores que recayeron sobre los prestatarios, quienes tuvieron que pagar intereses sobre intereses hasta poderlas cancelar totalmente. Un ejemplo fue el préstamo que benefició mancomunadamente en 1852 a los señores Ignacio y Juan Salcedo por valor de $\$ 660$ pesos de ocho décimos, pactado para ser pagado en un plazo de un año y con un interés del $2,5 \%$ mensual $^{17}$. Pero no

16 Tabla elaborada por el autor mediante escrituras de obligaciones y cancelaciones.

17 Escritura de obligación (1852), ANPB, ff. 125-126. 
fue cancelado en 12 meses, sino en 24, por lo tanto, los deudores pagaron la suma de $\$ 1.056$ pesos de esta forma: $\$ 660$ por el capital prestado y $\$ 396$ por el concepto de intereses corrientes.

Tabla 5. Número y valor de cancelaciones entre 1849 y $1853^{18}$

\begin{tabular}{|c|c|c|}
\hline Año & No. Cancelaciones & Valor en pesos de ocho déimos \\
\hline 1849 & 0 & 0 \\
\hline 1850 & 0 & 3.060 \\
\hline 1851 & 3 & 0 \\
\hline 1852 & 0 & $9.320,86$ \\
\hline 1853 & 17 & $12.380,86$ \\
\hline TOTAL & 20 & \\
\hline
\end{tabular}

Fuente: ANPB, 1849-1853

Otro caso fue la transacción crediticia realizada el 9 de enero de 1852 entre el prestamista Esteban Márquez y la prestataria Juana González por valor de $\$ 175$ pesos de ocho décimos. El plazo para su cancelación fue fijado en 6 meses. Sin embargo, el pago se hizo el 9 de enero de 1853, es decir, 6 meses después de lo convenido. En consecuencia, la señora González pagó la suma de $\$ 63$ pesos de ocho décimos por el concepto de intereses y $\$ 175$ por el préstamo ${ }^{19}$.

Posteriormente de un mal período en los pagos de las acreencias, vino uno de recuperación durante los años de 1854-1858 (ver Gráfico 1). En este lapso, los recaudos por cancelaciones pasaron de $\$ 12.380,86$ pesos de ocho décimos a $\$ 49.709,55$, es decir, se cuadruplicaron. También hubo un aumento significativo en el ritmo de los préstamos, los cuales pasaron de $\$ 63.788,9$ pesos a $\$ 102.564,41$, respecto al período anterior. El crecimiento presentado tanto en la suma de los capitales prestados como en los recaudados de las cancelaciones fue estimulado por la bonanza ocurrida en el sector exportador durante esos años ${ }^{20}$. En ella las exportaciones

18 Tabla elaborada por el autor.

19 Escritura de cancelación (1853), ANPB, t. único, f. 1, e. 1.

20 Marco Palacios y Frank Safford, Colombia. País fragmentado, sociedad dividida (Bogotá: Norma, 2002), 365-448. También véase: Salomón Kalmanovitz, Economía y Nación: una breve historia de Colombia (Bogotá: Siglo XXI Editores, 1988), 174-177. 
alcanzaron un valor de $\$ 4,9$ millones, comparables a un máximo de $\$ 1$ millón en décadas anteriores ${ }^{351}$. Por ende, las ciudades portuarias como Barranquilla se beneficiaron económicamente de este auge que incrementó las actividades comerciales y financieras, estimulando a su vez la llegada de un número considerable de comerciantes nacionales y extranjeros que abrieron casas comerciales para la explotación de los cultivos de la Costa ${ }^{21}$. Según el autor citado, la cercanía geográfica de Barranquilla con las zonas productoras de tabaco como El Carmen de Bolívar fue determinante para que se transportara y comercializara dicho producto desde este puerto hacia los mercados europeos, de esta forma, esta ciudad pudo beneficiarse del ciclo del tabaco.

Después de un crecimiento sostenido, el comportamiento de las transacciones crediticias y las cancelaciones se desplomaron durante 1859-1863 (ver Gráfico 1 y Tabla 3), solo se realizaron 40 préstamos por un total de $\$ 16.533$ pesos de ocho décimos. La cifra más baja de nuestro estudio. El número de las cancelaciones también cayó de 67 a 40, y los recaudos por este concepto disminuyeron de $\$ 49.709,55$ pesos a $\$ 27.817$ (ver Tabla 4). Lo anterior fue producto de la depresión en las exportaciones de tabaco y quina experimentada entre 1858 y 186122; también por la guerra civil que estalló en julio de 1859 hasta 1861. Ante estos sucesos, los comerciantes-prestamistas prefirieron guardar o invertir sus capitales en otros sectores más estables de la economía, pues para la mayoría de los colombianos la guerra significaba escasez y reclutamiento forzoso en cualquier momento por parte de los ejércitos en conflicto ${ }^{23}$. En otras palabras, estos factores crearon un estado de zozobra e inestabilidad en el mercado local, creando retención y fugas de capitales hacia otros negocios ${ }^{24}$.

Luego del desplome experimentado, el sector tuvo un crecimiento signifi-

21 Eduardo Posada Carbó, "El puerto de Barranquilla: entre el auge exportador y el aislamiento, 18501950", Caravelle (1988-), (1997): 119-132.

22 José Antonio Ocampo, Colombia y la economía mundial, 1830-1910 (Bogotá: Siglo XXI, 1984) 110111.

23 Richard Preston, El crédito y la economía, 135.

24 Tomás Caballero Truyol, Créditos, monedas, comerciantes y prestamistas. El mercado financiero en Barranquilla entre 1849 y 1903, Historia Caribe, No. 18 (2011), 156. 
cativo en el período de 1864-1873 como se observa en el Gráfico 1. Esta dinámica puede explicarse porque desde comienzo de la década de 1860 una parte de la población de la provincia de Barranquilla había mejorado sus condiciones de vida, gracias a los aumentos de los jornales que se duplicaron por la alta demanda de mano de obra que hubo para la explotación de los cultivos de tabaco y algodón. Pero a pesar de los aumentos en los salarios, las familias barranquilleras se vieron en la necesidad de recurrir al crédito para satisfacer sus necesidades socioeconómicas porque fue una época de malas cosechas por consecuencia de una sequía prolongada que encareció los productos básicos para la alimentación como los granos y los combustibles ${ }^{25}$.

Al respecto, Erasmo Rieux, gobernador de la provincia de Barranquilla en 1870, señaló:

La pérdida de las cosechas en tres años consecutivos por la escasez de lluvias, hizo encarecer los granos i demas comestibles, hasta el extremo mas desesperante; $i$ aunque este año hubo una cosecha abundante de algodón, esta apenas ha servido para pagar una parte de las deudas que tenían contraidas los cosecheros, apremiados por la necesidad - El hombre no reflexiona y se puede asegurar que los labriegos comprometieron tres años de su trabajo en el porvenir, i será preciso que transcurran éstos, con buenas cosechas, para que puedan pagar, i vuelvan los negocios de agricultura a seguir su curso regular ${ }^{26}$.

Podemos inferir que este fenómeno natural disparó el endeudamiento de los cosecheros y labradores de la ciudad, quienes tuvieron que comprometer sus trabajos y sus cosechas futuras para conseguir créditos. Sin embargo, este factor no significó un estancamiento en los pagos de las obligaciones, por el contrario, hubo un crecimiento vertiginoso en relación a los años anteriores (ver Gráfico 1), gracias a que los jornales subieron y la

25 Eduardo Posada Carbó, The Colombian Caribbean. A regional history, 1870-1950 (New York: Oxford University, 1996), 34-35.

26 Sergio Paolo Solano, "Informe Anual del Gobernador de la Provincia de Barranquilla, 1870", Memorias. Revista Digital de Historia y Arqueología desde el Caribe No. 10 (2009): 445-483. 
buena cosecha del algodón permitió a los prestatarios cumplir con el pago de sus acreencias.

Luego de casi una década de crecimiento de los capitales invertidos en el sector crediticio, hubo un período de decaimiento entre 1874 y 1878 (ver Gráfico 1). Uno de los factores que afectó su dinámica fue el estancamiento de las exportaciones tradicionales (tabaco, añil y quina) que cayeron a menos de la mitad en 1875. Este hecho repercutió negativamente en la economía local, causando pérdidas en varios negocios. Por esta razón, un número significante de casas comerciales y comerciantes se quedaron ilíquidos para solventar deudas, comprar mercancías y conceder nuevos créditos. Un caso fue el del mercader Ernesto Ebarbach, quien manifestó el 12 de febrero de 1877 no poder aceptar la letra de cambio a favor de Ebarbach \& Cía. por no tener fondos para cubrirla ${ }^{27}$.

Sumado a lo anterior, la guerra civil de 1876-1877 generó un período de incertidumbre en el sistema bancario y financiero del país, diversos bancos regionales y nacionales experimentaron una crisis de confianza por la guerra y la caída de las exportaciones de tabaco ${ }^{28}$. Esta situación causó escasez de capitales en el ámbito local y nacional, forzando a algunos comerciantes-prestamistas a retirarse del mercado para no ser víctimas de conceder préstamos de manera involuntaria al ejército regular e irregular. Un ejemplo lo encontramos en la demanda interpuesta por el prestamista don Esteban Márquez, quien en 1877 exigió al gobierno de los Estados Unidos de Colombia el pago de $\$ 1.500$ pesos de ocho décimos por el concepto de un crédito que les concedió durante ese año en Santa Marta de manera voluntaria y también por el valor de 12 reses de su propiedad que fueron tomadas por las autoridades políticas de la Ciénega de Santa Marta para financiar la guerra por cuenta de la nación ${ }^{29}$. Como consecuencia de este tipo de hechos, los agiotistas y mercaderes prefirieron invertir poco en este sector para evitar los riesgos de perder sus capitales y esperar meses o años para recuperarlos por medio de los estrados judiciales.

27 "Letra de cambio" (1877), ANPB, t. I, e. 160.

28 Marco Palacios y Frank Safford, Colombia. País fragmentando, 437-438.

29 "Poder especial" (1877), ANPB, t. único, e. 119. 
El miedo de los inversionistas de ser expropiados de sus bienes materiales para costear el conflicto bélico originó una restricción de capitales y préstamos en el comercio local, situación que afectó económicamente a diversas familias de la ciudad como la del clérigo Pedro María Revollo, quien señaló que 1877 "fue un año para nosotros de miseria"30. En términos económicos, la guerra civil de 1876 y 1877, originó escasez de alimentos, capitales y pobreza en gran parte de la población de Barranquilla.

Otro factor que afectó las dinámicas económicas de la ciudad fueron los graves daños ocasionados en la agricultura por las plagas de langostas que devastaron centenares de cultivos durante los años de 1877 y $1878 . \mathrm{Mu}-$ chos cultivadores, labradores, comerciantes, entre otras personas, que dependían económicamente de diversos cultivos como el tabaco, perdieron considerables sumas de dinero. Por ello, los propietarios de las sementeras fueron auxiliados por las autoridades locales mediante subsidios en dinero y productos agrarios para la reactivación del campo. Por ejemplo, el Estado de Bolívar decretó la Ley 59 de 1878, la cual dispuso la suma de $\$ 20.000$ pesos para reemplazar los cultivos afectados y minimizar los daños económicos sufridos en la población ${ }^{31}$.

En este orden de ideas, los años de 1870 fue una década de dificultades para las familias y los comerciantes barranquilleros, quienes tuvieron que padecer desastres naturales, conflicto bélico y crisis en el comercio internacional. Todos estos factores económicos y extraeconómicos incidieron para que los comerciantes-prestamistas guardaran sus capitales con el fin de mantener la solvencia económica que algunos habían perdido por las coyunturas descritas anteriormente. En efecto, las transacciones crediticias se desplomaron por causas de las incertidumbres económicas y políticas vividas durante esos años como se observa en el Gráfico 1.

En resumen, el ciclo del crédito inició con una fuerte demanda de préstamos para diversos fines entre los períodos de 1849-1853 y 1854-1858.

30 Pedro María Revollo, Mis memorias (Barranquilla: Editorial Mejoras, 2002), 38.

31 Ley 59 de 1878, leyes expedidas por la Asamblea Legislativa del Estado Soberano de Bolívar en las sesiones de 1878 y 1879 (Cartagena: Tipografía Antonio Araújo, 1880), 92. 
Luego, decayó y se estancó su crecimiento por la volatilidad de la economía local y nacional que creció levemente por causa de las guerras civiles, la escasez de personal para trabajar en sementeras y labores portuarias, las plagas, las enfermedades, los desastres naturales, entre otros factores que jugaron en contra de su crecimiento.

\section{ENTRE El AUGE Y El DECAIMIENTO DEL CRÉDito}

Después de varios períodos de crecimiento y descrecimiento en el comportamiento del crédito, vino uno de auge en 1879-1883. Como se observa en el Gráfico 1, fue el pico más alto que tuvo el ritmo del crédito durante la segunda mitad del siglo XIX. Durante este tiempo los capitales invertidos en este sector de la economía pasaron de $\$ 46.038$ pesos de ocho décimos a $\$ 252.562$,2; asimismo, hubo incremento significativo en los recaudos de las cancelaciones que pasaron de $\$ 56.744$ pesos de ocho décimos a $\$ 111.495$.

El alto endeudamiento de los barranquilleros y el buen comportamiento en el pago de las acreencias fue el resultado de la bonanza cafetera y ganadera que dejaron grandes utilidades en el sector exportador ${ }^{32}$. Esta coyuntura fue aprovechada por los comerciantes costeños para invertir considerables sumas de capital en empresas ganaderas y posteriormente diversificar parte de las utilidades obtenidas hacia otros reglones más riesgosos, pero más rentables como el financiero ${ }^{33}$.

Otro factor que disparó las transacciones crediticias fue la invasión de la langosta volátil que se cernió sobre los pueblos del Caribe colombiano en 1882. La plaga devastó en la provincia de Barranquilla centenares de hectáreas de plantas y cultivos generando escasez de alimentos vegetales para

32 José Antonio Ocampo, Colombia y la economía, 12.

33 Los negocios relacionados con la ganadería fueron atractivos durante esos años por la alta demanda que hubo en el mercado caribeño y especialmente el antillano sobre los productos ganaderos como consecuencia de la Guerra de los Diez Años que afectó la dinámica cubana como uno de los principales proveedores de carnes hacia dichos comercios. Véase: Sergio Solano y Jorge Conde, Élite empresarial y desarrollo industrial en Barranquilla 1875-1930, 1993, 9-20; y Reinaldo Funes Monzote, "Especialización azucarera y crisis de la ganadería en Cuba, 1790-1868”, Historia agraria: Revista de agricultura e historia rural, No. 57 (2012): 105-134. 
el hombre y los animales. Como consecuencia hubo hambruna, miseria y agotamiento de la vida ${ }^{34}$. Estos hechos llevaron a muchas familias barranquilleras a adquirir deudas para satisfacer sus necesidades económicas porque los precios de los productos básicos como los cereales y las frutas se habían encarecidos y algunos tuvieron que ser importados como el arroz para abastecer el mercado costeño por la falta de algunos víveres que se producían en la región ${ }^{35}$.

Después del auge, las operaciones crediticias que se contrajeron en 18841888, cayeron severamente en comparación al período anterior. El desplome fue el resultado de diversos factores socioeconómicos que afectaron las dinámicas del comercio local y nacional. Uno de ellos fue el estancamiento en el sector exportador como resultado de la crisis quinera y la caída de los precios internacionales del café ${ }^{36}$ que propiciaron el declive del flujo de mercancías y pasajeros movilizados por el puerto de Barranquilla como se observa en la Tabla 6. Sumado a lo anterior, la guerra civil de 1885, entre liberales y conservadores, profundizó aún más la crisis de este puerto porque fue tomado por el ejército rebelde del general Gaitán Obeso como estrategia militar para bloquear el transporte de tropas y suministros de armas y de alimentos por el río Magdalena ${ }^{37}$. Por consiguiente, el flujo de toneladas y el ingreso de vapores por esta rada decayeron severamente (ver Tabla 6).

Tabla 6. Estadística de los buques y vapores marítimos que entraron al puerto de Barranquilla desde 1877 a 1886

\begin{tabular}{|c|c|c|c|c|}
\hline Años & Vapores & Tonelaje & Buques de Vela & Tonelaje \\
\hline 1877 a 1878 & 13 & 50050 & 48 & 9593 \\
\hline 1878 a 1879 & 19 & 18186 & 35 & 6036 \\
\hline 1879 a 1880 & 25 & 20047 & 91 & 14242 \\
\hline 1880 a 1881 & 9 & 7676 & 134 & 20618 \\
\hline
\end{tabular}

Tabla 6. (Continúa p.134)

34 Pedro María Revollo, Mis memorias, 52.

35 María Aguilera Díaz, et al., Composición de la economía de la región Caribe de Colombia, Ensayo sobre economía regional, No. 013863, Banco de la República, 2013; también véase: Roicer Flórez Bolívar, "Economía agrícola y circuitos comerciales en el Estado Soberano de Bolívar, 1857-1886", Memorias, No. 16 (2012): 131-164.

36 José Antonio Ocampo, Colombia y la economía, 12.

37 Malcom Deas, Del poder y la gramática (Bogotá: Tercer Mundo Editores, 1993), 121-173. 
Tabla 6. (Viene p.133)

\begin{tabular}{|c|r|r|r|r|}
\hline 1881 a 1882 & 1 & 334 & 66 & 11482 \\
\hline 1882 a 1883 & 16 & 6212 & 39 & 7333 \\
\hline 1883 a 1884 & 5 & 3500 & 36 & 6433 \\
\hline 1884 a 1885 & & & 4 & 629 \\
\hline 1885 a 1886 & 1 & 484 & 6 & 1110 \\
\hline 1886 & & & 1 & 235 \\
\hline Total & 89 & 106489 & 460 & 77711 \\
\hline
\end{tabular}

Fuente: Fernando Baena y José Ramón Vergara, Barranquilla, su pasado y su presente

(Barranquilla: Cámara de Comercio, 1922), 12

Las actividades comerciales entre los diferentes puertos del río Magdalena también se estancaron, originando escasez de ciertos alimentos que inflaron sus precios a ultranza. Por ejemplo, en 1885, el clérigo Pedro Revollo señalaba que el precio de una gallina pasó de costar 4 reales (cuarenta centavos) a 5 pesos $^{38}$. Igualmente, algunos viajeros de la época como Elías Pellet relataron el estado de miseria que padecieron los habitantes de Barranquilla durante la guerra. Él describió que una cuarta parte de la población tenía por cama una sola estera extendida en el suelo húmedo, y que hubo pocos alimentos que básicamente consistieron en carne, pescado, plátano y bollo ${ }^{39}$.

La situación se tornó más grave cuando los comerciantes-prestamistas restringieron los créditos y exigían sus pagos en plazos más cortos para evitar la devaluación de la moneda del Banco Nacional de curso forzoso que se despreciaba por las continuas emisiones realizadas por dicho banco desde 1886, sin ningún tipo de respaldo en metálico ${ }^{40}$. Este hecho llevó a los comerciantes de la ciudad a realizar algunas transacciones monetarias y financieras en divisas extranjeras como el peso americano, el franco, la libra esterlina, entre otros medios de pago, para evitar pérdidas por la devaluación monetaria ${ }^{41}$. También a la imposición de cláusulas donde los

38 Pedro María Revollo, Mis memorias, 98.

39 Elías Pellet, "20 años en Barranquilla 1866-1886”, en Barranquilla y Sabanilla durante el siglo XIX 40 Juan Santiago Correo, "Del radicalismo a la regeneración. La cuestión monetaria (1880-1903)", Revista de Economía Institucional, Vol. 21 (2009):161-178.

41 Tomás Caballero Truyol, "Créditos, monedas, comerciantes y prestamistas, 147-153. 
prestatarios se obligaban a pagar el porcentaje de depreciación que podía sufrir la moneda cuando se cancelara la totalidad de un préstamo.

Una evidencia se encuentra en la operación crediticia realizada el 31 de agosto de 1887 por la señora Mariana Hamburger a favor de Manuela Matos de Corcho por la suma de $\$ 1.300$ pesos en moneda del Banco Nacional donde se estableció que el otorgante indemnizaría al prestamista en billetes el valor demérito que estos tuvieran en relación al cambio con la plata y en dicha porción del $20 \%$ cuando se verificara algún pago ${ }^{42}$.

Todos estos factores crearon un mercado muy riesgoso para los intereses de los prestamistas, quienes retuvieron sus capitales para invertirlos cuando volviera el orden público en el país. En otras palabras, la economía se encontraba resquebrajada por consecuencia de la guerra causando desempleo y una severa inflación que afectó las dinámicas económicas, restringió los créditos y llevó a los prestatarios a suspender el pago de sus acreencias por no existir recursos económicos para suplirlas ${ }^{43}$.

Después de un período negativo para el crédito, vino uno de recuperación y crecimiento en 1889-1893. En este lapso, el número de las transacciones crediticias aumentaron de 64 a 93 en comparación al período anterior; igualmente, los capitales invertidos en créditos se multiplicaron de $\$ 74.018,97$ pesos de ocho décimos a $\$ 149.192,13$. Este incremento fue posible por la combinación de diversos factores que jalonaron las inversiones en el sector financiero. Uno de ellos fue la leve recuperación que tuvo el sector exportador por el mejoramiento de los precios de intercambios que dejaron grandes dividendos a los comerciantes, quienes canalizaron parte de las utilidades obtenidas hacia el mercado financiero por las cuantiosas sumas de dineros que eran solicitadas por el gobierno local y nacional para construir obras públicas como el Ferrocarril Bolívar, por ejemplo, obra que estuvo a cargo del cubano Francisco Cisneros y financiada mediante un crédito de 70.000 libras esterlinas ${ }^{44}$.

42 "Escritura de obligación” (1887), ANPB, t. II, e. 143.

43 Malcom Deas, Del poder, 66.

44 "Escritura de obligación" (1887), ANPB, t. II, e. 113; y "Escritura de obligación” (1887), ANPB, t. II, e. 316. 
El padre Pedro Revollo indica que después de la revolución de 1886, tomó un gran impulso el progreso de Barranquilla y toda la República. Hubo mejoras considerables en la navegación a vapor por el río Magdalena, la introducción del telégrafo y otros vehículos más del progreso. Todas las obras civiles que comenzaron a construirse en la ciudad fue el resultado de inversiones extranjeras que se fomentaron en toda América Latina con el fin de crear una infraestructura idónea para exportar de una manera rápida y económica materias primas que necesitaban los países desarrollados para sus industrias y mercados ${ }^{45}$.

Sin embargo, la prosperidad económica vivida en el sector crediticio no benefició a toda la población porque las políticas monetarias implementadas durante la presidencia de Rafael Núñez causaron una alta inflación que afectó la calidad de vida de los habitantes. Sus ingresos percibidos por diferentes fuentes de trabajos como jornaleros, por ejemplo, no eran suficientes para satisfacer sus necesidades económicas en un mercado donde los productos de primera necesidad se habían encarecido en un $500 \%{ }^{46}$. Sin lugar a dudas, el endeudamiento se disparó como se observa en el Gráfico 1, pues las personas tuvieron que recurrir al crédito para poder solventar de alguna manera la situación económica que se tornó difícil durante esos años.

Finalmente, las fluctuaciones del comercio llevaron nuevamente a la caída de los créditos en 1894-1898. Como consecuencia, los capitales transferidos en este sector pasaron de $\$ 149.192,13$ pesos de ocho décimos a $\$ 74.230$, es decir, decrecieron en un $50 \%$ en comparación con el período anterior. Pero hubo un incremento por encima del $100 \%$ en el pago de las obligaciones que pasaron de $\$ 93.961,5$ pesos de ocho décimos a $\$ 229.011,96$. La caída de los créditos y el crecimiento en sus pagos están relacionados con la bonanza cafetera vivida en el país entre 1893-1898. Durante este período, el puerto de Sabanilla fue uno de los más benefi-

45 Ciro Cardoso y Héctor Pérez Brignoli, Historia económica de América Latina, Vol. II (Barcelona: Crítica, 1999), 105-210; también véase: Yadel Richard Apud, "Exportación de capitales hacia América Latina, dependencia y subdesarrollo", Observatorio de la Economía Latinoamericana, No. 153 (2011).

46 Juan Santiago Correo, Del radicalismo a la regeneración, 161-178. 
ciados al incrementar las exportaciones de café de 5.550 sacos a 126.500, representando el $30 \%$ de los exportados ${ }^{47}$. En este sentido, la prosperidad del sector portuario jalonó la economía de la ciudad. Al respecto, el clérigo Pedro María Revollo señala que desde 1886, Barranquilla mostró un progreso material ${ }^{48}$. Todos estos factores se tradujeron en un mercado financiero más estable con una buena dinámica en los pagos de las acreencias vencidas que superaron por primera vez las sumas transferidas como préstamos (ver Gráfico 2).

En resumen, los fenómenos políticos, sociales, económicos, naturales y bélicos influyeron directa e indirectamente sobre el comportamiento del crédito, creando un mercado volátil, fluctuante y riesgo, pero lucrativo para los comerciantes-prestamistas.

\section{REFLEXiOnes FinALES}

La escasez monetaria que existió en el comercio local llevó a los mercaderes a reemplazar su uso por mecanismos financieros que garantizaron su circulación. El principal documento utilizado fue la escritura de obligación porque se adaptó rápidamente a las condiciones y características de los negocios realizados mediante créditos con o sin el gravamen de un bien raíz o inmueble. Asimismo, la volatilidad del mercado local y las condiciones económicas de la mayoría de los prestatarios obligaron a los comerciantes-prestamistas a imponer su utilización con el fin de garantizar el retorno de sus capitales transferidos en préstamos a cortos y medianos plazos. De esta manera, cuando no era posible recuperar las inversiones realizadas con documentos de obligaciones, los acreedores, recurrían a las cláusulas jurídicas existentes en ellas para hacer valer sus derechos por la vía judicial.

Por último, la volatilidad del mercado creó un ritmo financiero dinámico por los avatares sociales, políticos y económicos que afectaron su comportamiento en diferentes períodos. Esto no fue un impedimento para que los

47 Luis Ospina Vásquez, Industria y protección en Colombia, 1810-1930 (Medellín: ESF, 1974), 364.

48 Pedro María Revollo, Mis memorias, 98-99. 
comerciantes-prestamistas se lucraran con las actividades crediticias que eran riesgosas, pero rentables a largo plazo. Por esta razón, aprovecharon las coyunturas para beneficiarse de las alzas, los estancamientos y las crisis, otorgando créditos onerosos para los prestatarios, quienes debían cumplir con sus acreencias sin importar la situación económica existente en el mercado.

\section{Bibliografía}

\section{Fuentes primarias}

Archivo Notaría Primera de Barranquilla (ANPB).

Código Civil Nacional. Bogotá: Imprenta de Gaitán, 1873.

Leyes del Estado Soberano de Bolívar, 1871-1879. Cartagena: Tipografía Araújo, 1880.

Pellet, Elías. "20 años en Barranquilla 1866-1886”. En Barranquilla y Sabanilla durante el siglo XIX (1852-1898), editado por Iveth Flórez y José Llanos. Barranquilla: Clío Caribe, 1995.

Reclus, Élisée. Viaje a la Sierra Nevada de Santa Marta. Bogotá: Colcultura, 1992.

Revollo, Pedro María. Mis memorias. Barranquilla: Editorial Mejoras, 2002. Solano D., Sergio Paolo. "Informe Anual del Gobernador de la Provincia de Barranquilla, 1870”. Memorias. Revista Digital de Historia y Arqueología desde el Caribe No. 10 (2009): 445-483.

\section{Fuentes secundarias}

Acuña Mantilla, Kelly y Andrés Álvarez. "De la moneda metálica al billete de banco en Medellín y Bogotá (1871-1885): Complementariedad y sustitución de medios de pago en un Régimen de banca libre". Revista Tiempo \& Economía, No. 1 (2014).

Aguilera Díaz, María, Yuri Reina Aranza, Antonio Orozco Gallo, Javier Yabrudy Vega y Rosemary Barcos Robles. "Composición de la economía de la región Caribe colombiana”. Ensayo sobre economía regional No. 013863. Banco de la República, 2013. Apud, Yadel Richard. "Exportación de capitales hacia América Latina, dependencia y subdesarrollo". Observatorio de la Economía Latinoamericana, No.153 (2011). 
Avella, Mauricio. Pensamiento y política monetaria en Colombia, 18861945. Bogotá: Contraloría General de la República, 1987.

Baena, Fernando, y José Ramón Vergara. Barranquilla, su pasado y su presente. Barranquilla: Cámara de Comercio, 1922.

Bergquist, Charles. Café y conflicto en Colombia 1886-1910. Bogotá: Banco de la República y el Áncora Editores, 1999.

Caballero Truyol, Tomás. "Créditos, monedas, comerciantes y prestamistas. El mercado financiero en Barranquilla entre 1849 y 1903”. Historia Caribe, No. 18 (2011): 145-164.

Caballero, Carlos, y Miguel Urrutia. Historia del sector financiero colombiano en el siglo XX. Bogotá: Editorial Norma, 2006.

Cardoso, Ciro, y Héctor Pérez Brignoli. Historia económica de América Latina, Vol. II. Barcelona: Crítica, 1999.

Castro Vargas, Hernando. "La sociedad barranquillera, entre los elementos tradicionales y modernos (1850-1885)". Memorias, No. 10 (2009): 297-335.

Colmenares, Germán. "Censo y capellanías: formas de crédito en una economía agrícola”. Cuadernos Colombianos No. 2 (1974): 123-143.

Correo, Juan Santiago. "Del radicalismo a la regeneración. La cuestión monetaria (1880-1903)". Revista de Economía Institucional, Vol. 21(2009): 161-178.

Deas, Malcolm. Del poder y la gramática. Bogotá: Tercer Mundo Editores, 1993.

Del Ángel, Gustavo y Carlos Marichal. "Poder y crisis: historiografía reciente del crédito y la banca en México, siglos XIX y XX”. Historia mexicana, Vol. 52, No. 3 (2012): 677-724.

Flórez Bolívar, Roicer. "Economía agrícola y circuitos comerciales en el Estado Soberano de Bolívar, 1857-1886”. Memorias, No. 16 (2012): 131-164.

Funes Monzote, Reinaldo. "Especialización azucarera y crisis de la ganadería en Cuba, 1790-1868”. Historia agraria: Revista de agricultura e historia rural, No. 57 (2012): 105-134.

García Heras, Raúl. "Deuda externa, banca internacional y política económica: los comienzos de una relación perdurable en la Argentina 1955-1973". Revista de la historia de la economía y de la empresa, No. 8 (2014): 345-377.

Kalmanovitz, Salomón. Economía y Nación: una breve historia de Co- 
lombia. Bogotá: Siglo XXI Editores, 1988.

Melo, Jorge. "La evolución económica de Colombia, 1830-1900”. En Nueva Historia de Colombia, Tomo II. Bogotá: Planeta, 1980.

Meisel, Adolfo. El Banco de la República: antecedentes, evolución y estructura. Bogotá: Editorial Banco de la República, 1990.

Moreno Torres, James. "Precios, oferta monetaria y crecimiento económico en la Nueva Granada de la segunda mitad del siglo XVIII". Revista de Economía Institucional, Vol. 15, No. 29 (2013): 195-225.

Ocampo, José Antonio. Colombia y la economía mundial, 1830-1910. Bogotá: Siglo XXI, 1984.

Ospina Vásquez, Luis. Industria y protección en Colombia, 1810-1930. Medellín: ESF, 1974.

Palacios, Marco, y Frank Safford. Colombia. País fragmentado, sociedad dividida. Bogotá: Norma, 2002.

Posada Carbó, Eduardo. The Colombian Caribbean. A regional history, 1870-1950. New York: Oxford University, 1996.

Posada Carbó, Eduardo. Una invitación a la historia de Barranquilla. Bogotá: CEREC, 1987.

Preston, Richard. "El crédito y la economía". En Sociedad y economía en el Valle del Cauca, Tomo IV. Bogotá: Biblioteca Banco Popular, 1983.

Quiroz, Alfonso W. Banqueros en conflicto: estructura financiera y economía peruana, 1884-1930. Lima: Centro de Investigación/Universidad del Pacífico, 1989.

Quiroz, Alfonso W. "Grupos económicos y decisiones financieras en el Perú, 1884-1930”. Apuntes: Revista de Ciencias Sociales, No. 19 (2015), 73-108.

Rougier, Marcelo (compilador). La banca de desarrollo en América Latina. Luces y sombras en la industrialización en la región. Buenos Aires: Fondo de Cultura Económica, 2011.

Sastoque, Edna y Mario García. "La guerra civil de 1876-1877, en los Andes nororientales colombianos”. Economía Institucional, Vol. 12., No. 22 (2010),193-214.

Solano, Sergio y Jorge Conde. Élite empresarial y desarrollo industrial en Barranquilla 1875-1930. Barranquilla: Universidad del Atlántico, 1993. 
Solano, Sergio Paolo. "Formas salariales y salario justo en el Caribe colombiano, 1850-1930”. Revista Amauta, No. 15 (2010), 159-181.

Solano, Sergio Paolo, "Informe Anual del Gobernador de la Provincia de Barranquilla, 1870”. Memorias. Revista Digital de Historia y Arqueología desde el Caribe No. 10 (2009), 445-483.

Solís, Ricardo. "La crisis gemela (los problemas de la balanza de pagos y bancaria) de 1913 y sus efectos en la moneda y los bancos". América Latina en la historia económica, Vol. 23, No. 3 (2016), 115-146.

Solórzano, Marcia Luz. “Banca extranjera en América Latina (1830-1910), una alternativa de transformación de las relaciones deuda-crédito". Revista Nicolaita de Estudios Económicos, Vol. 2, No. 2 (2013), 77 95.

Urrutia, Miguel, y Olga Marcela Namen León. Historia del crédito hipotecario en Colombia. Bogotá: Universidad de los Andes, 2011.

Von Wobeser, Gisela. "Mecanismos crediticios en la Nueva España el uso del censo consignativo". Mexican studies/Estudios mexicanos, Vol. 5, No. 1 (1989), 1-23.

Zegarra, Luis Felipe. "Women and credit in Peru during the guano era. Was there gender discrimination in the mortgage credit market of Peru?”. Historia Económica, No. 32 (2014): 151-185.

Para citar este artículo: Caballero Truyol, Tomás. "El uso obligatorio de la escritura notarial en las transacciones comerciales en Barranquilla, 1849-1898", Historia Caribe Vol. XIII No. 32 (Enero-Junio 2018): 115141. DOI: http://dx.doi.org/10.15648/hc.32.2018.5 